\title{
Revisiting euphemisation strategies for English to Indonesian subtitle context
}

\author{
SF. Luthfie Arguby Purnomo * 1, Ikke Dewi Pratama ${ }^{2}$, Lilik Untari ${ }^{3}$, SF. Lukfianka \\ Sanjaya Purnama ${ }^{4}$, Novianni Anggraini ${ }^{5}$ \\ 1,3,4 English Letters Department, Cultures and Languages Faculty, Institut Agama Islam \\ Negeri Surakarta, Sukoharjo, Indonesia \\ ${ }^{2,5}$ English Education Department, Cultures and Languages Faculty, Institut Agama Islam \\ Negeri Surakarta, Sukoharjo, Indonesia \\ * luthfiearguby@iain-surakarta.ac.id (Corresponding Author)
}

Received: September 3, 2019 Accepted: July 13, 2020 Published: September 8, 2020

\begin{abstract}
Character equivalence and offensive word rank in subtitling context are understudied on the previous studies on euphemisation strategies. The exclusion of these two concerns leaves the prior constructed euphemisation strategies unable to explain how shifts on narrative identity might occur and how taboo words are functionally negotiated. In addressing this issue, the study investigates the relationship between offensive word levels with character equivalence and narrative identity, types of euphemisation strategies, and the strategies' implementation. The data were collected from the English and Indonesian versions of four films containing taboo words, which were analyzed by applying the theories of offensiveness rank by Ofcom, constructed in English as a foreign language context, and character equivalence by Petrucci. The findings indicate that offensive word translation suffers a rank shift on offensive word ranks Departing from these findings. We propose euphemisation strategies with offensive word rank and character equivalence as the primary narrative basis with mediality and subtitling standard as the primary mechanical basis. Those strategies are downgrading, degrading, sidegrading, outgrading, ingrading, and retrograding. The reasons of euphemisation strategy implementation are bipolarly divided into aesthetics and mechanics in relation to distances and perspectives of the applied offensive words.
\end{abstract}

Journal on English as a Foreign Language, 10(2), 222-245

p-ISSN 2088-1657; e-ISSN 2502-6615 
Keywords: euphemisation strategies; offensive word rank; English to Indonesian subtitle context; character equivalence; audiovisual translation

How to cite this paper (in APA style): Purnomo, SF., L. A., Pratama, I. D., Untari, L., Purnama, SF. L. S., \& Anggraini, N. (2020). Revisiting euphemisation strategies for English to Indonesian subtitle context. Journal on English as a Foreign Language, 10(2), 222-245. https://doi.org/10.23971/jefl.v10i2.1480

DOI: https://doi.org/10.23971/jefl.v10i2.1480

The presence of offensive words in literary works like films contributes to the emergence of narrative identity, a postulation of one's identity with life experiences one has undergone (Ricœur, 2008). Serving as an identity for certain works implies the presence of what Petrucci (2012) terms as character equivalence, the identity literary works like films have. In the case of offensive words, problems occur when the words are translated into different languages for different cultures. The possibilities for shifts of character identities are eminent due to different cultural norms and ethics. Regarding these differences, euphemisation plays its part in negotiating narrative messages and translation functionality.

In the context of Audiovisual Translation (AVT), euphemisation strategies are constructed and implemented by taking medial concerns on the media to which AVT is exercised. Al-Adwan (2015) proposes a model of euphemisation strategies for film subtitles. In his model, he proposes two strategies namely semantic misinterpretation and omission. In relation to the equivalence, this model, besides concerning semantic equivalence, also considers the functional equivalence subtitling features. This functional consideration implies that mediality is taken into account on the construction of the model. Similar medial consideration is also perceptible from the study of euphemisation strategies in dubbing by Sedighi and Najian (2012). In their study, they propose norm related strategies, namely euphemism, censorship, or manipulation. These three strategies have a different degree of negotiation between mechanical concerns of lip synchronization and narrative concerns of message transfer, with euphemism posing as the most complex strategy in negotiating the two concerns. That euphemism is the most frequent strategy used to translate taboos, as indicated from the study findings, points out that mediality ushers certain complexities when intertwined with message transfer.

Journal on English as a Foreign Language, 10(2), 222-245

p-ISSN 2088-1657; e-ISSN 2502-6615 
This mediality in subtitling context refers to the fact that subtitles are exposed to the problems of spatial constraints, where character numbers compel the translators to negotiate between message accuracy and subtitle standard to trigger what Pedersen (2017) suggests as functional equivalence. Thus, translators are required to have not only considerations on linguistic, psychosexual, and religious differences as suggested by Chen (2004); but also the actants where the translation takes place (Westin, 2013), and the media where the subtitles are applied as implied by Nedergaard-Larsen (1993) and Eldalees et al. (2017).

In the scope of screen translation, the functional aspects of offensive words and euphemisation encompass not only their functionality but also subtitle and media functionality. Thereby the semantic meaning of particular euphemized offensive words is dependent on the functional aspects surrounding those words. This dependence implies that the aspects of stylistics are required to be taken as a concern in constructing euphemisation strategies as implied by Allan and Burridge (1991), who propose circumlocution, abbreviation, omission, and substitution. Each strategy might correspond to certain problems carried by certain offensive words, signifying the emphatic roles of stylistic perspectives in euphemisation.

Generally, the primary problem offensive words convey circumvents around emotive expressions and how the terms are articulated. Each of the problems requires a specific strategy to cope with the media's functionality, where the subtitles are applied. Regarding euphemisation for screen translation, the transfer of emotion conveyed by certain offensive words also requires consideration of the degree of importance the emotion has.

In the case of offensive word translation, risks on the emergence of identity shifts are also eminent since offensive words in literary works are a part of literary devices used to identify certain characters mimetically. This idea of identification is implied from Thomson (1935), indicating that swearing is usable as a tool to notice whether the situations in which the swearing occurs are unorganized or organized. In an unorganized situation, the swearing tends to evoke an unhappy situation while in an organized situation, a happy situation is identified. Swearing is generally used to identify the group (Tysdahl, 2008), intimacy and connection (Winters \& Duck, 2001), pain (Stephens et al. 2009) (Stephens \& Umland, 2011), impoliteness or politeness (Dynel, 2012), contextual appropriateness (Jay \& Janschewitz, 2008), an impression (Cavazza \& Guidetti, 2014), and humor (Beers Fägersten, 2017).

Journal on English as a Foreign Language, 10(2), 222-245

p-ISSN 2088-1657; e-ISSN 2502-6615 
Further, offensive words not only relate themselves to the identification of a particular situation but also become the identity of the speakers. Stapleton (2010) suggests that one of the four main functions of swearing through offensive words is to construct certain personal and social identity. Due to this function, if offensive words are translated into a different language, a shift might occur, and one of the shifts is in the change on the rank of offensiveness. Through this shift, a change in identity might occur. Furthermore, given the fact that subtitles narrate a story and in a narrative context, as signified by Karachaliou \& Archakis (2015), swearing and identity construction are interwoven and interdependent in a narrative context.

Ofcom (2016) surveyed the British swearing level, and the findings indicate four levels of offensiveness, namely mild, medium, strong, and strongest. In English as a foreign language context, this classification implies that swearing has a hierarchical rank, from which a translation has to address to preserve the intended meaning of the original expressions. This survey result also implies that the offensive word-level might suffer from a shift when translated into different languages due to the presence of different levels of the offensiveness. Baines (2016) argues that the shift on offensiveness level does not have clear impacts on characterization since the presence of linguistic and visual cues from the film does not generate any vivid differences in the effect.

As the primary concern of this study, users treat subtitles functionally, and thereby this study indicates findings, which tend to be functional, in which subtitles, as stated by Gottlieb (2018), are not a primary concern in the media industry. Thus, even the viewers might comprehend a subtitle-less film through the film's visual attributes though the languages are alien for them. Meanwhile, as seen from stylistic perspectives, Fox (2016) argues that since film texts contribute to the establishment of tone, subtitlers might have to consider this stylistic aspect of the film. Taking this statement, offensive words, as one of the literary devices that contribute to a film's overall tone, require a thorough consideration in translating them with offensiveness level as one of the concerns.

The importance of adhering functional and stylistic perspectives in film subtitling has also been the concern of Gottlieb (1994), stating that subtitles must have a literary translator's sensitivity. In the case of offensive words, this necessity to adhere stylistic perspectives, as seen from the study by Hjort (2009), covers whether the information certain offensive words carry is significant or not, from which the application of certain translation strategies is dependent

Journal on English as a Foreign Language, 10(2), 222-245

p-ISSN 2088-1657; e-ISSN 2502-6615 
upon. This selection on the degree of information offensive words carries further signifies the linkage between the semantic, stylistic, and medial aspects of offensive words. From these three aspects, translation and subtitling strategies are devised, and one of them is euphemisation.

The gaps left by the previous studies are the concerns on offensive word rank, character equivalence, and narrative identity. Departing from this gap, this research attempts to answer three problem statements, "How offensive word levels are related to character equivalence and narrative identity?", "What types of euphemisation strategies can be proposed from considering the link between offensive word level and character equivalence?", and "How the proposed euphemisation strategies are implemented on a translation study?"

\section{METHOD}

\section{Research Design}

This research was qualitative and descriptive in design. This research employed an integrative model of film and its audiovisual translation by Chaume (2004), emphasizing the codes film language has. Codes of audiovisual translation are intertwined, as the approach. Employing Chaume's model means approaching subtitles as codes, as a part of the film language. The approach was integrated with a narrative identity theory (Ricœur, 2008) to signify subtitles' role as narrative codes, from which subtitles were identified their possession of certain narrative identity. In applying these approaches, first, offensive words from The Fate of the Furious, The Wolf of Wall Street, Deadpool, and Rush Hour 3 were collected based on the categories of swearing words by Hughes (2006) and classified based on the offensiveness ranks by Ofcom (2016) proposed. Second, the collected and classified offensive words were analyzed to reveal how they contribute to the film characters' characterization and how they signify the film's overall tone. Narrative discourse by Genette (1990) was applied in this second step. Third, the shifts on character equivalence, which sum up the overall narrative identity, were analyzed by comparing the source's offensiveness levels and target offensive word rank. Fourth, proposing euphemisation types, which adhere to the consideration of offensive word rank and character equivalence.

\section{Data Sources}

This research's data are offensive words found from the sources of data; namely, the Indonesian subtitled The Fate of the Furious, The Wolf of Wall Street, Deadpool, and Rush Hour 3. The interlingual subtitle files in. SRT format was

Journal on English as a Foreign Language, 10(2), 222-245

p-ISSN 2088-1657; e-ISSN 2502-6615 
extracted and accessed by utilizing Aegisub program. Aligning and matching techniques to indicate verbal conformity were also implemented by referring to the film scripts. These films were selected since they depict different motif based narrative identities resulted from the exploitation of offensive words, different tones through the use of offensive words in the characterization, different narrative functions as seen from character establishment and development, and different genres about the offensive words used. The following table might clarify these reasons.

Table 1. Narrative identities, tones, and genres of the selected films

\begin{tabular}{|c|c|c|c|}
\hline Titles & $\begin{array}{c}\text { Motif based narrative } \\
\text { identities }\end{array}$ & $\begin{array}{l}\text { Offensive words } \\
\text { related tone building }\end{array}$ & Genres \\
\hline $\begin{array}{l}\text { The Fate of the } \\
\text { Furious }\end{array}$ & $\begin{array}{l}\text { Family through the } \\
\text { car-related motif }\end{array}$ & Non-central & $\begin{array}{l}\text { Car racing based } \\
\text { action }\end{array}$ \\
\hline $\begin{array}{l}\text { The Wolf of } \\
\text { Wall Street }\end{array}$ & $\begin{array}{l}\text { Hedonism through the } \\
\text { animal-related motif }\end{array}$ & Central & Autobiographical \\
\hline Deadpool & $\begin{array}{l}\text { Carefree through the } \\
\text { sex-related motif }\end{array}$ & Central & Action superhero \\
\hline Rush Hour 3 & $\begin{array}{l}\text { Intercultural } \\
\text { Communication } \\
\text { through the western } \\
\text { and eastern motif }\end{array}$ & Non-central & Action comedy \\
\hline
\end{tabular}

As seen in Table 1, the four films have different motif based narrative identities, making them interesting to discuss from offensive word usage perspectives. These differences were expected to reveal what offensive words were used to preserve the motif-based narrative identities. When particular offensive words are centrally used in the films, it implies that they function as a literary device to channel the film themes. Since centrality or non-centrality of the offensive word usage contributes to the construction of genres, it implies that offensive words have literarily functioned in the films whether to transfer themes or messages.

\section{Data Collection}

The data were collected from the srt files or subtitle ripped texts of each film. The .srt files were extracted by utilizing Aegisub. Utilizing this subtitle making freeware, the researchers could obtain all of the textual elements the films have in the form of subtitles. Through Aegisub, the researchers read the subtitles and indicated where the subtitles appeared in the films.

Journal on English as a Foreign Language, 10(2), 222-245

p-ISSN 2088-1657; e-ISSN 2502-6615 


\section{Data Analysis}

This research employed domain, taxonomy, and componential analyses by Spradley (2016). In domain analysis, data that could meet the category of offensive words as set by Hughes (2006) were grouped based on the category of profane or taboo. After the grouping was exercised, taxonomy analysis was executed by linking the offensive word grouping with the source's offensiveness level and target words to reveal which group suffered the most shift, the tone each film attempts to build, and the identity each film indicates. The theories of narrative discourse, narrative identity, character equivalence, and a report on offensive word rank were applied in the analysis phase to indicate a taxonomic link between the findings and the theories. In the last phase of analysis, componential analysis, euphemisation strategies were also constructed from the findings and the link between the offensive words with offensiveness level and character equivalence.

\section{FINDINGS}

\section{The Relationship between Offensive Word Level with Character Equivalence and Narrative Identity}

The findings indicate that offensive words found from The Fate of the Furious, The Wolf of Wall Street, Deadpool, and Rush Hour 3 are dominantly classified into taboo, with the word fuck and shit as the most dominant words. The following Table 2 is the dominant taboo words for each film.

Table 2. Dominant taboo word frequency

\begin{tabular}{ccc}
\hline Titles & Dominant taboo word & Frequency \\
\hline The Fate of the Furious & Shit & 20 \\
The Wolf of Wall Street & Fuck & 561 \\
Deadpool & Fuck & 60 \\
Rush Hour 3 & Damn & 12 \\
\hline
\end{tabular}

Table 2 indicates that foul language becomes the primary concern of the films in constructing characterization for the characters and further indicates that they contribute to the film tones. In the case of Rush Hour, the racial slur negro appears once to strengthen Carter's presence as a black character, the counterpart for Lee, Carter's white Asian partner.

Shit in The Fate of the Furious was translated mostly into sial (lit. an expression of bad luck). The offensiveness level suffers from a shift since shit is categorized medium in offensiveness while sial is mild. That sial in Bahasa

Journal on English as a Foreign Language, 10(2), 222-245

p-ISSN 2088-1657; e-ISSN 2502-6615 
Indonesia, to a certain degree, is not considered taboo emphasizes a distortion on the characterization of the characters that express the word since shit tends to be taboo with a higher degree of emotion than sial. In The Wolf of Wall Street, the translation of fuck, due to its diverse functions, is varied. The pattern found from the translation of fuck is that when it comes to what Jay (1992) calls as strong emotion as found from motherfucker, the emotion that the word attempts to convey is preserved by translating it into bajingan (lit. scoundrel), the strongest offensive word on the same offensiveness level as fuck and its derivative forms.

On the other hand, the translator does not translate fuck in Bahasa Indonesia when the word is expressed in a manner (Jay, 1992) calls as mild forms of anger or to indicate what Hughes (2006) puts it as a habit of swearing. Meanwhile, uniquely fuck appearing on scenes where Jay (1992) calls as attempts to control anger, is euphemized into sial or brengsek (lit. incompetent). These translations occur mostly on the scenes where the boss-worker relationship is shown, implying that the translator attempts to preserve business nuance in the film's dark humor tone.

A different tone the word fuck attempts to build is perceptible from the superhero film Deadpool. The word fuck in this film is mostly combined with other sex-related terms and is delivered in a dark comedy tone. To preserve this tone identity, interestingly, the translator translates fuck into explicit sex-related terms. Put a bullet in his skull and fuck the brain hole is translated into menembak kepalanya dan onani di lubang otaknya (lit. shoot his head and masturbate in his brain hole). The act of self-sex, as indicated by the choice of the word onani points out that the translator attempts to preserve the tone identity by explicating self-sex into onani. As exercised on the example dominantly, explanation occurs on other sex-related terms indicating that the translator comprehends well that the narrative identity the film attempts to construct by relying on the presence of sex-related terms. Meanwhile, damn in Rush Hour 3, is consistently translated into sial, implying the absence of offensive word rank shift since damn and sial are of the same milder rank. That the garrulous Carter is the speaker of the word damn, not the silent Lee, indicates an attempt from the film to construct a distinctive difference between the West and the East, which becomes the film's motif.

The above explanation implies that concerns and considerations on character equivalence, which shape a film's overall narrative identity, are existent. Regarding this condition, euphemisation strategies are applied as a

Journal on English as a Foreign Language, 10(2), 222-245

p-ISSN 2088-1657; e-ISSN 2502-6615 
negotiation tool between the offensiveness rank of particular taboo words, film tone, character equivalence, and narrative identity. This treatment as a negotiation tool is visible from the fact that the translation of offensive words from the three films tends to classify first the significant level of narrative information that particular offensive words bear before deciding to apply euphemisation. Offensive words without strong emotion, which emit significant narrative information, tend to be omitted. This omission is a part of euphemisation strategies, which considers the mediality and standard of subtitles, especially on the character usage limitation.

Meanwhile, the translators attempt to preserve the speakers' characterization and tone identity by aligning the offensive word rank to ensure that the offensive level is similar. The findings indicate that the translators also euphemize offensive words with significant narrative information by selecting equivalent words, which are assumed to retain the films' tone. For example, in The Wolf of Wall Street, the translator carefully translates bitch into either pelacur or jalang. Both mean whore with jalang having a more specific meaning on having a character like that of an animal. In the case where the word bitch is directed to women with rebellious attitudes and unlawful business activities, jalang is applied. This decision signifies the attempt to align the animal symbolization of wolf from the selected word jalang. That jalang leaves a stronger emotive impression than that of pelacur further intensifies the tone identity the film tries to construct.

Departing from these findings, this article proposes euphemisation strategies based on considerations on offensive word rank and character equivalence, from which narrative identity is constructed, with the mediality and standard of subtitle as the mechanical concerns.

\section{Types of Euphemisation Strategies}

We propose six types of euphemisation strategies with offensive word rank and character equivalence as the basis. They are downgrading, degrading, sidegrading, outgrading, ingrading, and retrograding. The use of the word grading for the euphemisation strategies is the reflection of the offensive word rank. The following Table 3 might help quickly comprehend the types and their functions.

As seen in Table 3, downgrading works by lowering the offensive word rank in the target language, degrading by omission, sidegrading by concerning on the media and standard, outgrading by description, ingrading by

Journal on English as a Foreign Language, 10(2), 222-245

p-ISSN 2088-1657; e-ISSN 2502-6615 
preservation, and retrograding by keeping the aesthetics of the film. The details of each strategy are described in the following subsections.

Table 3. Types and functions of the proposed euphemisation strategies

\begin{tabular}{cl}
\hline Types & \multicolumn{1}{c}{ Functions } \\
\hline Downgrading & $\begin{array}{l}\text { Lowering the rank of particular offensive words in the target } \\
\text { language } \\
\text { Omitting offensive words due to the insignificant narrative } \\
\text { information the words carry } \\
\text { Euphemizing the offensive words to overcome the problems of } \\
\text { mediality and standard } \\
\text { Outgrading }\end{array}$ \\
$\begin{array}{l}\text { Descriptively translating the meaning of the offensive words } \\
\text { Preserving narrative information } \\
\text { Retrograding }\end{array}$ & $\begin{array}{l}\text { Retaining the aesthetics aspects of a film with multiplicities } \\
\text { through a faithful translation over particular offensive words }\end{array}$ \\
\hline
\end{tabular}

Downgrading

The first type of the proposed euphemisation strategies is downgrading. Applying this euphemisation strategy means lowering the rank of particular offensive words in the target language. The shift of offensiveness level to a lower rank is the focus of this euphemisation strategy. The translation of shit to sial in The Fate of the Furious, as discussed above, is the example of downgrading since the offensive word rank suffers a shift from medium to mild.

In downgrading, though the offensiveness level is lowered, the translator still attempts to hold significant emotion and information carried by the offensive words. In Deadpool, the mercenary has a habit of calling somebody by mixing a particular feature that a person has with sex-related terms. When he is angry at Colossus, a mutant who can shapeshift his body into steel, he says you, big chrome cockgobbler! The word chrome refers to Colossus' steel body and cockgobbler is a sex related term directed to the mutant. The translator transfers the line into dasar penghisap burung dari kromium (lit. bird sucker made of chrome). Burung (lit. bird) in Bahasa Indonesia might refer to bird and the euphemistic version of penis. The choice over this word and the preservation of Colossus' steel body reference indicate the presence of negotiation between the necessity to concur to the target norms and the necessity to preserve the character equivalence. This decision to exercise this negotiation is made possible by concerning and considering offensive work rank.

Journal on English as a Foreign Language, 10(2), 222-245

p-ISSN 2088-1657; e-ISSN 2502-6615 
Degrading

The second type is degrading. This euphemisation strategy omits offensive words due to the insignificant narrative information the words carry. In this strategy, concerns on the mediality and the subtitle standard also play crucial roles in influencing the translators' decision in applying this strategy. As discussed before, the translator of The Wolf of Wall Street applies to degrade for the word fuck that contains insignificant narrative information by omitting it.

The concerns on the limited use of characters on subtitles also come to consideration. One of the examples is when Jordan Belfort, the main character, says And don't pick up your fucking head until 1:00. Hey, fuck him, which is translated into dan jangan angkat kepala sampai selesai. Persetan dengannya (lit. don't lift your head until done. Fuck him), appearing consecutively in 0.51 seconds. In this time gap, the translator has to cope with fucking, functioning as an emphasizer of warning, and fuck him, which has significant narrative information regarding the characterization of Jordan Belfort as a scurvy broker who has no concern over his clients. The translator decides to degrade the first fuck on fucking head and to preserve the second fuck on fuck him to settle the time gap problem. This decision indicates that an attempt to preserve the character equivalence through tone identity preservation is eminent.

\section{Sidegrading}

In degrading, omission might occur due to the mediality and the subtitle standard. Still, in sidegrading, instead of performing an omission over particular offensive words, the translator prefers euphemizing the offensive words to overcome the problems of mediality and standard. In sidegrading, the translator selects a word, among other words in the same rank of offensiveness with the fewest character. This selection over a word with the fewest character is applied based on a timing standard set by subtitling standards. Standards set by Karamitroglou (1998), for instance, allot 1.5 seconds for a single word appearance, 3 seconds for a line, 6 seconds for double lines, and 0.25 for subtitle interval. The choice of the word onani over masturbasi in Deadpool indicates the presence of sidegrading since onani has fewer characters but this case should be validated whether the appearance of certain expressions finds a problem on timing or not. In you mean my big, rubber, masturbating shoes? timing is an issue since its translation maksudmu sepatu karet onani besarku? is required to appear for 1.49 seconds with 0.01 second interval only, knowing that the expression is on a single line, standardized to appear for 3 seconds, and an interval of 0.25

Journal on English as a Foreign Language, 10(2), 222-245

p-ISSN 2088-1657; e-ISSN 2502-6615 
seconds. Onani saves few characters than that of masturbasi and that makes the translator have a flexible hand with the next lines.

\section{Outgrading}

Selecting offensive words with a lower rank in the target language pose a problem when such a word is not existent. One of the ways to overcome this problem is to describe the source offensive words euphemistically. One of the examples found from the data source is teabag, the slang of oral sex, expressed in Deadpool. The translator encounters aesthetics concerns in this case. The aesthetics concerns refer to teabag status as slang with offensive power, implying the necessity to preserve the sense of being slang when translated into the target language. In response to this aesthetics, the translator translates teabag into cium buah zakar (lit. kiss a penis), which is a descriptive action. By descriptively translating the meaning of teabag implies that slang with similar meaning in Bahasa Indonesia is not existent and further points out that the translator concerns transferring the message as vivid as possible to the viewers to assist them in capturing the tone of the film.

The problem with outgrading is the possible consumption of extra characters, triggering a lengthy expression. In the case of teabag, the translation is able to exercise outgrading since the expression stands alone. In the perspectives of offensive word rank, the description in outgrading is still in possession of offensiveness level though the expression is not that of word. As seen from cium buah zakar, the offensiveness level is perceptible from the fact that buah zakar is the euphemistic version of much stronger word, kontol (lit. penis). The combination it has with cium (lit. kiss) indicates the attempt from the translator to provide a lucid meaning over the Action of oral sex while at the same time euphemizing the object of the oral sex by lowering the rank.

Ingrading

Film like other types of literary works has what is called narrative information, from which closer or farther distance between a narration, a narrator, and a reader is constructed based on the level of detailed information the narrative shares to the readers (Genette, 1990). In The Wolf of Wall Street, for instance, a wolf's motif is presented throughout the film through semiotics and semantics manners. For instance, in semiotics manner, the symbolization of being in a pack like wolves is visualized through the shot depicting Jordan, when taking on a prey in the stock market, packing together with his men to execute their fraudulent marketing trick. Expressions, which denotatively and

Journal on English as a Foreign Language, 10(2), 222-245

p-ISSN 2088-1657; e-ISSN 2502-6615 
connotatively refer to animalistic behaviors like sex, greed, and power, flourishedly decorate the film. One of the examples, as discussed before, is the preference over the word jalang which has an animalistic side than pelacur, sharing similar prostitute meaning but in a different tone. This preference signifies the translator's attempt in preserving animalistic motif to align itself with the primary wolf motif for an aesthetics purpose.

A similar case is found from The Fate of the Furious on the word wanker. This offensive word, which refers to masturbation, is used to aesthetically strengthen the car and race motif the film has since wanker also refers to carrelated slangs, namely car wanker and bus wanker. Different from the case of jalang, where the translator manages to preserve the wolf motif of the film, in the translation of The Fate of the Furious, the translator fails to align the translation of wanker with the car and race motif. This failure on aligning the translation and the motif happens because the translator translates wanker into pengecut (lit. coward).

Retrograding

Like any other narratives, films have an intertextual power, enabling them to be made into sequels, prequels, spin-offs, remakes, or remasters. This intertextuality requires a cohesion in a narrative (Hernández-Pérez \& Ferreras Rodríguez, 2014). In narrative perspectives, this connection involves narrative information, from which tone and motif are consistently preserved.

For instance, in Rush Hour franchise, Carter always expresses himself with damn to indicate an unexpected situation in translating the film franchise into Bahasa Indonesia. The translator faithfully translates it to sial when Carter encounters an unexpected situation in the trilogy of Rush Hour. The faithful choice of the word sial indicates an attempt from the translator to retain the source and target word's offensiveness rank, intertextually preserve the character of Carter as being expressive, and intertextually keep the comic tone of the film. This faithful choice throughout a film's multiplicities, which are intertextually connected, is retrograding, focusing on retaining the aesthetics aspects of a film with multiplicities through a faithful translation over particular offensive words.

\section{The Application of the Proposed Euphemisation Strategies}

In applying these euphemisation strategies in translation studies, distances and perspectives are the axis, from which the studies should revolve. In concerning euphemisation, distances refer to the distance on the offensive

Journal on English as a Foreign Language, 10(2), 222-245

p-ISSN 2088-1657; e-ISSN 2502-6615 
word rank shift from the source to the target language. Meanwhile, perspectives refer to the ways euphemisation is presented to the viewers. The combination of distances, perspectives, and euphemisation strategies results in the implication types from particular strategies. The following Table 4 might help illustrate the implications translation texts might suffer from after the proposed euphemisation strategies are applied.

Table 4. Severity level of the proposed euphemisation strategies

\begin{tabular}{|c|c|c|c|c|}
\hline $\begin{array}{l}\text { Euphemisation } \\
\text { strategies }\end{array}$ & Distances & Perspectives & $\begin{array}{l}\text { Euphemisation } \\
\text { reasons }\end{array}$ & $\begin{array}{l}\text { Severity level } \\
\text { on character } \\
\text { equivalence }\end{array}$ \\
\hline \multirow[t]{8}{*}{ Downgrading } & \multirow[t]{4}{*}{ Adjacent } & \multirow[t]{2}{*}{ Aggregate } & Aesthetics & Major \\
\hline & & & Mechanics & Major \\
\hline & & \multirow[t]{2}{*}{ Fractional } & Aesthetics & Mild \\
\hline & & & Mechanics & Major \\
\hline & \multirow[t]{4}{*}{ Distant } & \multirow[t]{2}{*}{ Aggregate } & Aesthetics & Critical \\
\hline & & & Mechanics & Critical \\
\hline & & \multirow[t]{2}{*}{ Fractional } & Aesthetics & Major \\
\hline & & & Mechanics & Major \\
\hline \multirow[t]{8}{*}{ Degrading } & \multirow[t]{4}{*}{ Adjacent } & \multirow[t]{2}{*}{ Aggregate } & Aesthetics & Major \\
\hline & & & Mechanics & Critical \\
\hline & & \multirow[t]{2}{*}{ Fractional } & Aesthetics & Minor \\
\hline & & & Mechanics & Major \\
\hline & \multirow[t]{4}{*}{ Distant } & \multirow[t]{2}{*}{ Aggregate } & Aesthetics & Major \\
\hline & & & Mechanics & Critical \\
\hline & & \multirow[t]{2}{*}{ Fractional } & Aesthetics & Minor \\
\hline & & & Mechanics & Major \\
\hline \multirow[t]{8}{*}{ Sidegrading } & \multirow[t]{4}{*}{ Adjacent } & \multirow[t]{2}{*}{ Aggregate } & Aesthetics & Major \\
\hline & & & Mechanics & Mild \\
\hline & & \multirow[t]{2}{*}{ Fractional } & Aesthetics & Minor \\
\hline & & & Mechanics & Mild \\
\hline & \multirow[t]{4}{*}{ Distant } & \multirow[t]{2}{*}{ Aggregate } & Aesthetics & Critical \\
\hline & & & Mechanics & Mild \\
\hline & & \multirow[t]{2}{*}{ Fractional } & Aesthetics & Major \\
\hline & & & Mechanics & Mild \\
\hline \multirow[t]{7}{*}{ Outgrading } & \multirow[t]{4}{*}{ Adjacent } & \multirow[t]{2}{*}{ Aggregate } & Aesthetics & Minor \\
\hline & & & Mechanics & Critical \\
\hline & & \multirow[t]{2}{*}{ Fractional } & Aesthetics & Minor \\
\hline & & & Mechanics & Major \\
\hline & \multirow[t]{3}{*}{ Distant } & \multirow[t]{2}{*}{ Aggregate } & Aesthetics & Major \\
\hline & & & Mechanics & Critical \\
\hline & & Fractional & Aesthetics & Minor \\
\hline
\end{tabular}

Journal on English as a Foreign Language, 10(2), 222-245

p-ISSN 2088-1657; e-ISSN 2502-6615 


\begin{tabular}{|c|c|c|c|c|}
\hline \multirow{3}{*}{ Ingrading } & \multirow[b]{2}{*}{ Adjacent } & \multirow[b]{2}{*}{ Aggregate } & Mechanics & Major \\
\hline & & & Aesthetics & Major \\
\hline & & \multirow{3}{*}{ Fractional } & Mechanics & Minor \\
\hline \multirow{14}{*}{ Retrograding } & \multirow{6}{*}{ Distant } & & Aesthetics & Major \\
\hline & & & Mechanics & Minor \\
\hline & & \multirow[t]{2}{*}{ Aggregate } & Aesthetics & Critical \\
\hline & & & Mechanics & Major \\
\hline & & \multirow[t]{2}{*}{ Fractional } & Aesthetics & Major \\
\hline & & & Mechanics & Minor \\
\hline & \multirow[t]{4}{*}{ Adjacent } & \multirow[t]{2}{*}{ Aggregate } & Aesthetics & Critical \\
\hline & & & Mechanics & Mild \\
\hline & & \multirow[t]{2}{*}{ Fractional } & Aesthetics & Major \\
\hline & & & Mechanics & Mild \\
\hline & \multirow[t]{4}{*}{ Distant } & \multirow[t]{2}{*}{ Aggregate } & Aesthetics & Critical \\
\hline & & & Mechanics & Mild \\
\hline & & \multirow[t]{2}{*}{ Fractional } & Aesthetics & Major \\
\hline & & & Mechanics & Mild \\
\hline
\end{tabular}

Table 4 shows how distances and perspectives, which are the narrative information elements, are intertwined with the euphemisation strategy types. Distances refer to whether the euphemizing word is adjacent to the source word or distant from it in terms of the ranks of offensive words. Scholars have to refer themselves to particular theories discussing offensive word ranks for the source and target texts to reveal these distances. The following Table 5 might help differentiate between adjacent and distant distances

Table 5. Classification of distances

\begin{tabular}{cll}
\hline Distances & $\begin{array}{c}\text { Semantic relation to the source } \\
\text { word }\end{array}$ & \multicolumn{1}{c}{$\begin{array}{c}\text { Stylistic relation to the } \\
\text { source word }\end{array}$} \\
\hline Adjacent & From the same family & $\begin{array}{l}\text { Evoking similar emotion } \\
\text { Similar contexts }\end{array}$ \\
& Similar functions & Evoking dissimilar emotion \\
Distant & From a different family & Dissimilar contexts \\
& Dissimilar functions & \\
\hline
\end{tabular}

Semantic relation refers to offensive word rank, constructed based on whether the target word and the source one are in the same taxonomic family or not. Meanwhile, stylistic relation refers to the aesthetic usage of a particularly offensive word in the source and target text, focusing on whether the manner of emotion and context of the offensive word usage are classified in the same taxonomic family and prevalence or not. The consideration of employing semantic and stylistic relations is because both are intertwined in a major role in

Journal on English as a Foreign Language, 10(2), 222-245

p-ISSN 2088-1657; e-ISSN 2502-6615 
establishing narrative information for the works where they appear. As implied by Dobao (2006), semantics and stylistics have a reciprocal relationship, in which stylistic equivalence becomes as important as semantic when offensive words appear on a particular degree of appearance. After revealing the level of distance, an analysis of perspectives should take place.

Perspectives refer to the ways euphemisation strategies are applied, whether they are applied in an aggregated manner or a fractional one. An aggregate manner indicates that particular euphemisation strategies are dominantly selected to euphemize the source offensive words in a wide gap compared to other euphemisation strategies. On the other hand, fractional works are the opposite of aggregate, in which no euphemisation strategies are blatantly dominant from other strategies. Either aggregate or fractional perspectives are applied, their implicative concerns are connected to the reasons of euphemisation, namely aesthetics and mechanics.

Ethics, which becomes the basis of euphemisation, is not separately classified since its presence has already encompassed any euphemisation reasons the translators apply, meaning that aesthetics and mechanics are also ethics itself. Aesthetics refers to how literary elements, namely narrative information, which covers characterization, motif, and other literary elements, constructs a particular narrative identity. Meanwhile, mechanics refers to the subtitling mediality and subtitle standard. Euphemisation reasons, in their link with perspectives, signify whether the dominant use of aggregate or fractional perspectives is intertwined with the mechanics or aesthetics.

The appearance of aesthetics related aggregate perspectives indicates that particular euphemisation strategies are dominantly applied due to narrative information reasons, implying that subtitling mediality and subtitle standard are not of central problems. Contrarily the emergence of mechanics related aggregate perspectives highlights the significant influence of subtitling mediality and subtitle standard. Similar significances are also captured from aesthetics and mechanics related fractional perspectives with a difference in the fact that fractional indicates a diverse range of euphemisation strategies to overcome the problem of equivalence.

Similar to distances, perspectives, and euphemisation reasons are inseparable from the proposed euphemisation strategies. The relationship each euphemisation strategy has with distances, perspectives, and euphemisation reasons lie on the severity level of the euphemisation strategies. The following Table 6 shows the levels of severity.

Journal on English as a Foreign Language, 10(2), 222-245

p-ISSN 2088-1657; e-ISSN 2502-6615 
Table 6. Severity level classification

\begin{tabular}{cl}
\hline Severity level & \multicolumn{1}{c}{ Threatened narrative elements } \\
\hline Critical & Motif and most of the major characters \\
Major & Motif \\
Minor & Few major and minor characters \\
Mild & Minor characters \\
\hline
\end{tabular}

As seen in Table 6, there are four severity levels, namely critical, major, minor, and mild. Critical severity indicates that the euphemisation words threaten the overall character equivalence, which might result in a total alteration on the narrative identity of the film. Film identity might refer to fixity where characters, images, and modes of engagement must also conform to certain expectations or codes such that they can be apprehended and acknowledged by others (Cresswell \& Dixon, 2002). By fixity implies that a formulaic agreement between the film-makers and the audiences toward the identity of a certain film is existent and might derive from the film elements that could define the film's identity.

\section{DISCUSSION}

The primary reason behind the construction of offensive word rank and character equivalence based euphemisation strategies is the consideration that offensive words have offensiveness rank. In narrative like film, offensive words like swearing, as implied by Norrick (2012), are exploited by authors to signal emotions, from which character identity might be learned. In the context of subtitle, due to its ability to create lexical inference (Mitterer \& McQueen, 2009) through its multimediality, which encompasses the subtitling software, the media the subtitles are applied to, and other supporting subtitle and video related media (McLoughlin, 2009; 2010), the identity offensive words attempt to build is vulnerable for a shift. Thereby, in applying certain euphemisation strategies, translators should be concerned about the possibilities for a shift in the film identity.

This offensiveness rank is also narrative information, from which tone, motif, characterization, and other literary elements are constructed to signify a particular narrative identity. Character equivalence as the culmination of narrative identity is also constructed from particular literary works' narrative information. Therefore, strategies established with narrative information functioning as the core of work are assumed to elucidate more on how euphemism as narrative information, borrowing the term from Genette (1990),

Journal on English as a Foreign Language, 10(2), 222-245

p-ISSN 2088-1657; e-ISSN 2502-6615 
could reveal the degree of distance between literary works and their users and the perspectives the works have for the users.

The word fuck, for instance, is the most used swearing by the Americans. Still, its semantic meaning depends on the context of the situation (Jay, 1992), implying that a degree of importance on the information transmitted by offensive words is existent. Thereby, translators are compelled to omit words considered to be less important. This action to omit or to preserve particular information in consideration with the ranking of importance the information has signifies how mediality becomes a concern on the negotiation of meaning, how the application of euphemisation upon particular offensive words indicates the level of importance particular information has, and how the selection toward the level of importance of particular information might indicate the semantics and stylistics significances of the information. The presence of information importance level or ranking further indicates that offensive words require a consideration, which involves the offensive word ranks to assist translators in applying euphemisation on their subtitles.

In linguistics, especially English, language bridges the fixity and the film viewers in evoking certain codes that establish certain film identity. Due to the language's roles as a bridge, when the language is translated, the film identity might experience a shift since different languages convey and trigger different styles. In The Fate of the Furious, for instance, the world of the street race the film attempts to construct is not depicted only through the images but also the way the characters express themselves. Idiomatic and phrasal expressions like warm as turbo, behind the wheel, and you pulled my family through, which incorporate auto terms, signify the efforts the film has in constructing a world of street race through the use of racing-related-terms in the daily communication between the characters in the film world. In the Indonesian version, the translator attempts to preserve the presence of the auto terms by modulating warm as turbo into dinamo murah (lit. cheap dynamo) and behind the wheel into mengemudi (lit. drive) but the translators fail to transfer the racing term of pull through. This phrasal verb, having a meaning to put something in a dangerous situation, is also a wordplay of the word pull-through. This word play refers to a parking space, which allows a fast-paced exit, indicating the climax scene where the line appears. The translator transfers the message literally into yang kau lakukan pada keluargaku (lit. what you did to my family), omitting the racing nuance due to the absence of expression, which might bridge between the actual meaning of the phrasal verb and the auto terms, which are related to the hidden meaning.

Journal on English as a Foreign Language, 10(2), 222-245

p-ISSN 2088-1657; e-ISSN 2502-6615 
As seen from the preservation of the auto terms, this case indicates that the translator has a concern on the character equivalence of the film, from which certain identity is transmitted. In the translation perspectives, this problem on identity circumnavigates around what Gottlieb (2018) terms as the politics of audiovisual translation, in which rules and standards are set by the profit-oriented media industry and audiovisual translation industry tend to usher hegemony over translation itself. This condition opens susceptibility and vulnerability over the identity certain films attempt to build.

Major severity points out that the selected euphemizing words threaten the motif the film attempts to build. Minor severity signifies the presence of a threat from the applied euphemisation words on a few major and minor characters. Mild leaves a narrative threat only on minor characters. Comprehending the mentioned severity level classification, scholars of translation studies could comprehend the relationship among euphemisation strategies, distances, and perspectives constructed from narrative information, euphemisation reasons, and severity level on character equivalence. An example is given as follows to provide a clear comprehension of how the proposed euphemisation strategies are applied in the analysis.

In The Wolf of Wall Street, for instance, the presence of 561 fucks and their derivative forms implies the stylistic importance of the offensive word in establishing the tone and strengthening the animal motif of the word. 15 fucks are translated into bajingan, which stands on the same rank as fuck, 22 fucks are downgraded into sial and sialan, 11 fucks are downgraded into keparat, 2 fucks are ingraded into brengsek, and the rest 511 fucks are degraded. Since degrading is the most employed strategy, distances are not of concern, but perspectives are. Aggregate is the most dominant perspective in the execution of the euphemisation strategies since the word fuck, which dominantly appears and constructs the characterization and motif style, suffers from degrading on 511 words. This aggregation is exercised mostly due to mechanical problems, seen from the use of fuck as an emphasizing literary tool on daily expressions through its derivative forms like fucking and fucked up. By degrading the emphasizing fuck, the translator ushers flexibility of space to contain other narrative information, which is considered to be more crucial. This condition leads to a critical severity level of character equivalence since the characterization, for instance, Jordan Belfort as the main character, and the animal motif are exposed to a drastic shift in the target text.

Journal on English as a Foreign Language, 10(2), 222-245

p-ISSN 2088-1657; e-ISSN 2502-6615 
In regard to degrading as seen from the above example, confusion over degrading as a euphemisation or a censorship might arise. Degrading, due to its omitting act, evokes confusion whether this strategy belongs to euphemisation or censorship. According to Bourdieu, censorship is a euphemisation while Foucault, as a standalone disciplinary power (Etienne, 2013). If Bourdieu's statement is taken into account, the formulation of degrading in the proposed euphemisation strategies is correct. Meanwhile, if Foucault's opinion is considered, degrading might be censorship if euphemisation could prove itself to be interdisciplinarily linked. Scholars of translation studies with interests on euphemisation could propose taxonomy of omission with euphemisation and censorship as the consideration with a central focus on aesthetics, implications, and patterns.

\section{CONCLUSION}

Six types of euphemisation strategies are constructed, namely downgrading, degrading, sidegrading, outgrading, ingrading, and retrograding. The use of grading indicates and aligns with the offensive word rank, which becomes the central focus of the strategies. In implementing these strategies, one should concern what we call as distances and perspectives. Distances refer to how far the euphemizing word in the target text deviates from the source text. Perspectives refer to how the euphemisation is brought to the viewers. Departing from the analysis of distances and perspectives, the implementation of a particular euphemisation strategy might trigger an impact on the severity level of the translation quality. This severity level might indicate that the implemented euphemisation strategies might trigger critical, major, minor, or mild severity. The formulated strategies might be a helpful guide in comprehending how particular strategies might generate impacts on the mediality and stylistics of the subtitle. The proposed euphemisation strategies could be combined with subtitling strategies to perceive a comprehensive picture on how the two types of strategies are intertwined to generate narrative information for the film viewers.

\section{DECLARATION OF CONFLICTING INTERESTS}

The authors declared no potential conflicts of interest with respect to the research, authorship, and/or publication of this article.

Journal on English as a Foreign Language, 10(2), 222-245

p-ISSN 2088-1657; e-ISSN 2502-6615 


\section{REFERENCES}

Al-Adwan, A. S. (2015). Towards a model of euphemisation in Arabic subtitling. Arab World English Journal (AWEJ) Special Issue on Translation, 4(May), 6-21. Retrieved from https://awej.org/Index.php/specialissues/56-special-issue-on-translation-4-2015/648-amer-samed-al-adwan

Allan, K., \& Burridge, K. (1991). Euphemism \& dysphemism: Language used as shield and weapon. In Language in Australia and New Zealand (pp. 92-97). Oxford University Press.

Baines, R. (2016). Subtitling taboo language: Using the cues of register and genre to affect audience experience? Meta, 60(3), 431-453. https://doi.org/10.7202/1036137ar

Beers Fägersten, K. (2017). English-language swearing as humor in Swedish comic strips. Journal of Pragmatics, 121, 175-187. https://doi.org/10.1016/.pragma.2017.10.014

Cavazza, N., \& Guidetti, M. (2014). Swearing in political discourse: Why vulgarity works. Journal of Language and Social Psychology, 33(5), 537-547. https://doi.org/10.1177/0261927X14533198

Chaume, F. (2004). Film studies and translation studies: Two disciplines at stake in audiovisual translation. Meta, 49(1), 12-24. https://doi.org/10.7202/009016ar

Chen, C. (2004). On the Hong Kong Chinese subtitling of English swearwords. Meta, 49(1), 135-147. https://doi.org/10.7202/009029ar

Cresswell, T., \& Dixon, D. (Ed.). (2002). Engaging film: Geographies of mobility and identity. Rowman \& Littlefield.

Dobao, A. F. (2006). Linguistic and cultural aspects of the translation of swearing: The Spanish version of Pulp Fiction. Babel, 52(3), 222-242. https://doi.org/10.1075 babel.52.3.02fer

Dynel, M. (2012). Swearing methodologically: The (im)politeness of expletives in anonymous commentaries on Youtube. Journal of English Studies, 10, 25-50. https://doi.org/10.18172 亿es.179

Eldalees, H., Al-Adwan, A., \& Yahiaoui, R. (2017). Fansubbing in the arab world: modus operandi and prospects. Arab World English Journal For Translation and Literary Studies, 1(1), 48-64. https: //doi.org/10.24093 /awejtls/vol1no1.4

Etienne, A. (2013). Naked censorship: stripping the censors' discourse. Revue LISA / LISA e-Journal, Vol. XI- $n^{\circ} 3$. https://doi.org/10.4000 /isa.5509

Fox, W. (2016). "Should she really be covered by her own subtitle?": Text elements in film and their graphical translation. Translation Spaces, 5(2), 244-270. https://doi.org/10.1075/ts.5.2.05fox 
Genette, G. (1990). Narrative discourse: An essay in method (1. publ., 4. print). Cornell University Press.

Gottlieb, H. (1992). Subtitling-A new university discipline. In C. Dollerup \& A. Loddegaard (Ed.), Teaching Translation and Interpreting (pp. 161). John Benjamins Publishing Company. https://doi.org/10.1075/z.56.26got

Gottlieb, H. (1994). Subtitling: Diagonal translation. Perspectives, 2(1), 101-121. https://doi.org/10.1080/0907676X.1994.9961227

Gottlieb, H. (2018). The politics of audiovisual translation. In F. Fernández \& J. Evans (Ed.), The Routledge Handbook of Translation and Politics (1 ed., pp. 323-342). Routledge. https://doi.org/10.4324/9781315621289-21

Hernández-Pérez, M., \& Ferreras Rodríguez, J. G. (2014). Serial narrative, intertextuality, and the role of audiences in the creation of a franchise: an analysis of the indiana jones saga from a cross-media perspective. Mass Communication and Society, 26-53. https://doi.org/10.1080/15205436.2013.788192

Hjort, M. (2009). Swearwords in subtitles-a balancing act. InTRAlinea: Special Issue: The Translation of Dialects in Multimedia, Special Issue: The Translation of Dialects in Multimedia. Retrieved from http://www.intralinea.org/specials/article Swearwords_in_Subtitles

Hughes, G. (2006). An encyclopedia of swearing: The social history of oaths, profanity, foul language, and ethnic slurs in the English-speaking world. M.E. Sharpe.

Jay, T. (1992). Cursing in America: A psycholinguistic study of dirty language in the courts, in the movies, in the schoolyards, and on the streets. J. Benjamins Pub. Co.

Jay, T., \& Janschewitz, K. (2008). The pragmatics of swearing. Journal of Politeness Research. Language, Behaviour, Culture, 4(2). https://doi.org/10.1515/JPLR.2008.013

Karachaliou, R., \& Archakis, A. (2015). Identity construction patterns via swearing: Evidence from Greek teenage storytelling. Pragmatics and Society, 6(3), 421-443. https: //doi.org/10.1075/ps.6.3.05kar

Karamitroglou, F. (1998). A proposed set of subtitling standards in Europe. Translation journal, 2(2), 1-15.

McLoughlin, L. I. (2009). Subtitles in translators' training: A model of analysis. Romance Studies, 27(3), 174-185. https://doi.org/10.1179/174581509X455141

McLoughlin, L. I. (2010). Perspectives on audiovisual translation (Ł. Bogucki \& K. Kredens, Ed.). Peter Lang.

Mitterer, H., \& McQueen, J. M. (2009). Processing reduced word-forms in speech perception using probabilistic knowledge about speech 
production. Journal of Experimental Psychology: Human Perception and Performance, 35(1), 244-263. https://doi.org/10.1037/a0012730

Nedergaard-Larsen, B. (1993). Culture-bound problems in subtitling. Perspectives, 1(2), 207-240. https://doi.org/10.1080/0907676X.1993.9961214

Norrick, N. R. (2012). Swearing in literary prose fiction and conversational narrative. Narrative Inquiry, 22(1), 24-49. https://doi.org/10.1075/ni.22.1.03nor

Ofcom. (2016). Attitudes to potentially offensive language and gestures on TV and radio: Quick reference guide (pp. 15). Ipsos MORI. Retrieved from https://www.ofcom.org.uk/research-and-data/tv-radio-and-ondemand/tv-research/offensive-language-2016

Pedersen, J. (2017). The FAR model: Assessing quality in interlingual subtitling. Journal of Specialized Translation, 28(2017), 210-229.

Petrucci, P. (2012). The translation of cinematic discourse and the question of character equivalence in talk to me. Multilingua, 31(2-3). https://doi.org/10.1515/multi-2012-0011

Ricœur, P. (2008). Oneself as another (K. Blamey, Penerj.; Nachdr.). Univ. of Chicago Pr.

Sedighi, A., \& Najian, T. S. (2012). On audiovisual translation: The effect of norms of dubbing taboos into Persian movies after the Islamic revolution in Iran. Journal of Language and Translation, 3(1), 37-49.

Spradley, J. P. (2016). Participant observation. Waveland Press.

Stapleton, K. (2010). Interpersonal pragmatics (M. A. Locher \& S. L. Graham, Ed.). De Gruyter Mouton.

Stephens, R., Atkins, J., \& Kingston, A. (2009). Swearing as a response to pain: NeuroReport, 1. https://doi.org/10.1097 WNR.0b013e32832e64b1

Stephens, R., \& Umland, C. (2011). Swearing as a Response to Pain-Effect of Daily Swearing Frequency. The Journal of Pain, 12(12), 1274-1281. https://doi.org/10.1016 ßj.jpain.2011.09.004

Thomson, D. F. (1935). The joking relationship and organized obscenity in north queensland. American Anthropologist, 37(3), 460-490. https://doi.org/10.1525/aa.1935.37.3.02a00100

Tysdahl, B. (2008). Ibsen: the significance of swear-words. Ibsen Studies, 8(1), 6978. https://doi.org/10.1080/15021860701717852

Westin, J. (2013). Loss of culture: New media forms and the translation from analogue to digital books. Convergence: The International Journal of Research into New Media Technologies, 19(2), 129-140. https://doi.org/10.1177/1354856512452398 
Winters, A. M., \& Duck, S. (2001). You***!: Swearing as an aversive and a relational activity. In R. M. Kowalski (Ed.), Behaving badly: Aversive behaviors in interpersonal relationships. (pp. 59-77). American Psychological Association. https://doi.org/10.1037/10365-003

\section{Authors' Brief CV}

SF. Luthfie Arguby Purnomo received his master's and doctoral degree in translation studies from Sebelas Maret University. He is currently teaching video game localization and audiovisual translation in English Letters IAIN Surakarta. His research primarily revolves around translation studies and applied linguistics.

Ikke Dewi Pratama currently works as a lecturer in translation and linguistic studies in English Education and English Letters, IAIN Surakarta. She obtained her master's degree in translation studies from Sebelas Maret University in 2014. Her research focuses on translation and linguistic studies.

Lilik Untari received her doctorate in Humanities Sciences from Gadjah Mada University. Her recent publications include Prosthetic Translation: Retranslations of Video Game Remakes and Remasters Refute Retranslation (2019) and Semantics in Action, Meaning Representation in Children's Fiction (2019). She is currently teaching translation in English Letters IAIN Surakarta.

SF. Lukfianka Sanjaya Purnama received his master's degree in translation from Sebelas Maret University. He is currently teaching Subtitling and Web Translation in English Letters IAIN Surakarta. He is also working as a game developer and localizer. His research primarily revolves around translation studies and applied linguistics.

Novianni Anggraini received her bachelor from the Muhammadiyah University of Surakarta and a master's degree in English education from Sebelas Maret University. She is focusing on teaching English skills and Psychology. Her research areas circumnavigate around teaching in ELT. 